\title{
Clinical Trial Monitoring Plan
}

National Cancer Institute

\section{Source}

National Cancer Institute. Clinical Trial Monitoring Plan. NCI Thesaurus. Code C115753.

A proposed method to ensure the adequate monitoring of subjects during a clinical trial. 